University of Nebraska - Lincoln

DigitalCommons@University of Nebraska - Lincoln

Faculty Publications: Department of Teaching, Department of Teaching, Learning and Teacher Learning and Teacher Education

Education

2020

Identity Negotiation in Multilingual Contexts: A Narrative Inquiry into Experiences of an African Immigrant High School Student

Lydiah Kananu Kiramba

James Oloo

Follow this and additional works at: https://digitalcommons.unl.edu/teachlearnfacpub

Part of the Bilingual, Multilingual, and Multicultural Education Commons, Curriculum and Instruction Commons, and the Teacher Education and Professional Development Commons

This Article is brought to you for free and open access by the Department of Teaching, Learning and Teacher Education at DigitalCommons@University of Nebraska - Lincoln. It has been accepted for inclusion in Faculty Publications: Department of Teaching, Learning and Teacher Education by an authorized administrator of DigitalCommons@University of Nebraska - Lincoln. 


\title{
Identity Negotiation in Multilingual Contexts: A Narrative Inquiry into Experiences of an African Immigrant High School Student
}

\author{
Lydiah K. Kiramba' ${ }^{1}$ James A. Oloo ${ }^{2}$ \\ 1 Department of Teaching, Learning and Teacher Education, \\ University of Nebraska-Lincoln \\ 2 Department of Educational Administration, Policy and Leadership, \\ University of Windsor
}

\begin{abstract}
Background/Context: Inclusion of African immigrant youth voices in educational and research discourses remains rare despite the steady growth of this population in the United States over the past four decades. Consequently, the multilingual abilities of these youth remain typically unnoticed or ignored in the classroom, and little is specifically known about their histories, cultures, expectations, and achievements.

Purpose: Using the narrative inquiry approach and the Natural, Institutional, Discursive, Affinity, Learner, and Solidarity (NIDALS) theoretical lens, we explore the lived experiences of one African immigrant high school student in the midwestern United States.

Research Design: Using narrative inquiry (Clandinin \& Connelly, 2006), we qualitatively explored the lived cultural, racial, and ethnic identities and self-images experienced by a Ghanaian-born female high school student, Akosua (pseudonym), as she navigated and resisted identities ascribed to her in the midwestern U.S.

Findings: The student's narratives speak to issues of culture, identity, and self-image, as well as her literate life in multiple languages and literacy contexts in and
\end{abstract}

Published in Teachers College Record 122:13 (2020).

https://www.tcrecord.org/Content.asp?ContentId=23389

Copyright (c) 2020 Teachers College, Columbia University. Used by permission. 
out of school. The findings reveal narratives of ascribed identities, racialization, and perceived language hierarchies in the participant's daily life and indicate a need to challenge such narratives about African immigrant students and disrupt the reproduction of linguistic and racial inequality in the school system.

Recommendations: While school systems do follow state-sanctioned linguistic norms and ideologies, when educators draw on students' experiences and funds of knowledge as resources already in the room in order to find ways of negotiating and disrupting language hierarchies and the ascribed identities they support, it allows all students, including multilinguals, to have their identity affirmed, even in school systems that have historically marginalized them. This, in turn, supports educational achievement, broadly realized, not only psychologically for all students but also economically and nationally for the country-a critical accomplishment in an era when educational quality in the U.S. is losing ground to foreign achievements.

Studies on African immigrant students show that they often experience challenges due to their invisibility, linguistic and accent differences, stereotypes, and other factors (Kumi-Yeboah \& Smith, 2017). The students tend to experience different forms of marginalization, including being misidentified and discriminated against due to their cultural and linguistic difference (Kumi-Yeboah \& Smith, 2017). Moreover, the unique challenges of African immigrant students are rarely highlighted or addressed in their specificity within educational research and praxis. Agyepong (2013) has recounted stories of the marginalization she experienced as an African-born student in the United States (U.S.), which included speaking in a different English accent, manner of dressing and teasing based on stereotypes about Africa. Young immigrant self-accounts of their experiences are conspicuously rare in educational and policy research. While scholars have examined resilience and academic success among African immigrant students (Hersi, 2011; Kumi-Yeboah, 2016; Mwangi \& English, 2017), little research has foregrounded such students' experiences and how they navigate their new spaces. Even less disambiguates the often vast cultural differences of immigrants from various regions, tribes, or countries on the African continent.

Nonetheless, scholars have noted that many African immigrant students in the U.S. share an experience of marginalization based on classroom curricula (Ghong et al., 2007). Some curricular content about Africa has been reported to make students feel humiliated and ashamed about their heritage (Kumi-Yeboah \& Smith, 2017 Ukpodoku, 2016). As Awokoya (2013) has noted, pulling up long-standing and 
deep-rooted stereotypes about Africa in the U.S. remains an uphill task. It is also an uphill task to challenge those voices and narratives that embolden assimilation, effect erasure of the unique identities represented by African immigrants, and methodologically conflate African American and Africa students in U.S. classrooms. Highlighting and amplifying one African immigrant student's narratives in relation to school and socially ascribed identities, we employ the Natural, Institutional, Discursive, Affinity, Learner, and Solidarity (NIDALS) framework (Gee, 2000-2001; Razfar \& Rumenapp, 2013) as an analytic lens for approaching these identity narratives. Using narrative inquiry, we explore the high school student's self-images, experiences, and perceptions regarding both her multilingual literacy practices in and out of school and her identity construction in light of her storied experiences in the U.S. Our research is guided by the following questions:

1. What do the participant's lived experiences reveal about her culture, self-image, and identities across her country of origin and in the midwestern United States?

2. In what ways do the student navigate and negotiate (embrace or resist) socially ascribed identities?

While addressing these questions will enhance our understanding of the experiences of African-born immigrant youth in U.S. classrooms, it also has implications for school leaders and other educational stakeholders working with immigrant students to enhance educational success for those students. In an era when the U.S. education system prioritizes standardization (Darling-Hammond, 2010) despite increasingly diverse student populations (Kiramba \& Oloo, 2019), it becomes critical to understand where unintentional obstacles arise for students of any origin. In particular, language plays a crucial mediating role in both classroom discourse patterns and the social organization of the classroom.

\section{Literature review}

Having a clear understanding of one's identity allows young people to "make firm choices in areas like career goals, personal values, friendships, dating relationships, and family obligations" (Schwartz, et al., 
2015, p. 152). The psychological value of this for students notwithstanding, secure self-identity also facilitates citizenship and addresses workforce human resource challenges and the general well-being and economic security for society as a whole. As such, removing any barriers to the integration of immigrant children and youth is sound policy both psychologically and sociologically, locally and nationally. Note, however, that "integration" in this context does not mean assimilation. While assimilationist approaches to cultural and ethnic diversity presume that minority cultures and languages are deficient (Watt, 2006), we reject that notion, and concur with the view that "students' exposure to other students who are different from themselves and the novel ideas and challenges that such exposure brings leads to improved cognitive skills, including critical thinking and problem solving” (Wells et al., 2016, p. 18).

Moreover, while secure "ethnic identity promotes well-being and protects against anxiety, depression, behavior problems, and substance use" in students (Schwartz, et al., 2015, p. 155), it may also offset negative, stigmatizing experiences by immigrant students based on their languages and accents, their countries of origin, and prevailing stereotypes in school (Creese, 2010; Ghong et al., 2007). These negative experiences regularly erase or silence multiple (multilingual) competencies that immigrant students, and African immigrant students specifically, bring to the classroom (Creese, 2010). Kumi-Yeboah and Smith (2017), for instance, identified negative impacts on Ghanaian immigrant student relations with peers, teachers, and classroom participation due to differences in English language use. Medvedeva (2010) similarly found that perceived discrimination due to language use affected the confidence and linguistic adaptation among immigrant students. Notwithstanding the fundamental linkage of language and identity and its longterm psychological and social implications for people (Suárez-Orozco et al., 2015), the rationality of removing (and not reproducing) these kinds of barriers in order to achieve the best outcomes for all citizens personally and nationally makes itself self-apparent.

Additionally, stereotypes about Africans especially affect African immigrant youths' identity formation (Schroeter \& James, 2015). Watson and Knight-Manuel (2017) note that West African youth tend to downplay their identity as Africans owing to derogatory stereotypes. Covington-Ward (2017) acknowledges that there are problematic 
stereotypes and misconceptions about Africa and that dealing with stereotypes and misinformation is one of the primary issues that many African immigrants face in their everyday interactions with Americans (Okonofua, 2013). While Razfar and Rumenapp (2013) identify several prevailing stereotypes or assumptions about race, gender, and learning disorders, Brady (2015) indicates how teachers can take an active approach to forestall formation (or further development) of these educational barriers through the use of texts that afford all students the opportunity to connect with their history and culture and to contribute to a sense of self using reading, drama, and writing in the classroom.

While we would be remiss not to mention how language and the proliferation and maintenance of these stereotypes (particularly about "Africans") are intertwined, this specific point is too large to fully address here. Nonetheless, we acknowledge that linguistic power plays a key role (Kiramba, 2018)-for example, in the myth highlighted by Brady (2015) that "bad language signifies bad people" (p. 151)-not only in the way that it relatively positions and orders students differently (Dávila, 2019), but also in how it encourages immigrant students to position themselves (Kiramba \& Oloo, 2019). Against this linguistic power, however, students (and their communities) can (and do) resist in several ways (Allen et al., 2012; Dávila, 2019; S. Kim, 2018; Malsbary, 2014; Obsiye \& Cook, 2016; Watson \& Knight-Manuel, 2017).

In this study, we attempt to amplify one African immigrant high school student's narrative around self-perception and identity negotiation. We highlight the student's perception of self in complex and unique terms in the context of how she utilizes her languages and cultural skills to navigate spaces. While Akosua, the Ghanaian-born student, proudly refers to herself as "Ghanaian" and "African," the designation African itself stands in much like the misnomer "American" for people in the U.S. ("America," properly speaking, is the whole of the western hemisphere, including North and South America and the surrounding waters and islands, not just the U.S.). Like "American," "African" can offer a coherent and integrated self of identity that links together an otherwise disparate collection of ethnic/linguistic heritage and (sometimes) multiple countries of origin (see for example Kiramba \& Oloo, 2019). As used in this study, "African" is not intended to essentialize the continent or her people. 
While several studies have contributed significantly to our understanding of immigrant student experience in the U.S., gaps still exist in terms of how their experiences influence their identities of who they are becoming as students in their new spaces. Research studies have documented that specific voices of African immigrant and refugee Black children remain often unheard or unrecognized in their specificity in academic discourses. Although they comprise a significant part of the increasing multilingual learner population in U.S. classrooms, their cultural and linguistic assets which form a major part of their identity may similarly go unnoticed or unrecognized in their daily interaction with peers in and out of school. This study addresses that gap.

\section{Theoretical approach: The NIDALS framework}

Much scholarship notes the centrality of language for identity; for instance, "In sociocultural theories, language is a mediational tool through which identities are assumed and stances are taken to identify ourselves and others in socially organized activity systems" (Razfar \& Rumenapp, 2013, p. 269). Building on Gee's (2000-2001) model of situated and discursive identity, using the Natural, Institutional, Discursive, Affinity, Learner and Solidarity (NIDALS) framework, Razfar and Rumenapp (2013) show how interconnected and multilayered each identity is. For each of the six layers and perspectives represented by the initials NIDALS, there is an assumption of identity being influenced by an outside source.

The N-identity (or "natural") layer frames identity as an extension of nature, including markers like sex and race. Although N-identity factors remain essentially beyond one's control, students' abilities and potential for achievement or failure are sometimes judged based on their N-identity (Razfar \& Rumenapp, 2013). In contrast, the I-identity (or "institutional") layer frames identity in terms of formal sociocultural environments and emphasizes the governed, societally viewed interpretations of natural identities. Thus, for example, an individual is identified as a student because he or she attends a school. Race, gender, and ethnicity as social constructs, for instance, have institutionalized characters in spaces like school, church, work, and so on. In general, I-identities make us who we are because they are governed by the power of social and political legitimacy that precedes individual agency. 
If the N- and I-identity layers echo (and resist) the "self" versus "society" distinction, the D-identity (or "discursive") layer emphasizes the social interaction between them as engaged discourse. The way a person speaks, for example, can be interpreted as "an artifact of cultural membership" (Brown, 2015, p. 11) while also revealing an ethnicity or color depending on their dialect. D-identity especially points up the centrality of language as discourse with respect to identity. As a tool for interaction, language can also implicate both social class or one's social positioning within a space or time when a given dialect is deemed legitimate or illegitimate. Razfar and Rumenapp (2013), for instance, note how peers, teachers, and administrators can other immigrant students' D-identity through the students' use of nonstandard or accented English. This can then also impact the A-identity (or "affinity") and L-identity (or "learner") layers of identity, which concern both the affective and the ideological connections that bind community members to common immediate goals, practices, and larger purposes and the funds of knowledge and competencies that students bring to the institution of school, respectively. Failing to recognize these funds of knowledge can have manifold negative impacts (Kiramba, 2017; 2019; Kiramba \& Harris, 2019).

Taking these four NIDA layers together, the S-identity (or "solidarity") layer informs and impacts the student's L-identity (as a "learner"). Here again, language represents an integral component in terms of what Razfar and Rumenapp (2013) denote as indexicality: "Through indexicality we announce our identities and ideologies (the way we view and use language in a sociopolitical context) through the spoken and/or written word" (p. 278) and consequently ascribe identities to others after hearing the type of their language and the way they use it. This explains how "languages have skin colors" (Wolfenstein, 1993, p. 331), such that whiteness becomes an attribute of English. Consequently, "If you don't speak white you will not be heard, just as when you don't look white you will not be seen" (Wolfenstein, 1993, p. 331)-where such not being heard or not being seen can manifest as outright erasure or being ascribed an inaccurate (if not defamatory) identity through the lens of whiteness.

It must be stressed, however, that this situation requires no link to explicit racism (or antiracism) by the speaker. "In the absence of challenges to linguistic hegemony, indeed, language is white" (Wolfenstein, 
1993, p. 331, emphasis added). This points to the need for such hegemonic challenges-and to a rejection by school systems of any linguistic policies or hierarchies that (unconsciously) integrate this educational obstacle into peers', teachers', and students' D-identity layer within educational settings-which concern both the affective and the ideological connections that bind community members to common immediate goals, practices, and larger purposes and the funds of knowledge and competencies that students bring to the institution of school, respectively. From the perspective of indexicality, it is not that we can (if we even could) end the habit of ascribing (NIDALS) identities to one another, but that we might stop doing so in habitually negative ways.

\section{Positionality}

We are multilingual educators who immigrated to North America from Africa. While we have both experienced what Gluszek and Dovidio (2010) identify as a "stigma of nonnative accent" (p. 225), personal discussions and research with multilingual immigrant-origin families, especially those with school-age children, have also helped to shape this study and bring this issue into focus. These, together with our own lived experiences, have influenced this study and our retelling of the participant's story.

\section{Methodology}

\section{Data collection and analysis}

Consistent with narrative case study methods (Stake, 1995), we recruited and convenience sampled Akosua as a participant from our previous knowledge of the relevance of her background to the central phenomenon of this study: the lived, multilinguistic navigations of cultural, racial, and ethnic identities and self-images experienced by African-born immigrant high school students in the U.S.

Using narrative inquiry (Clandinin \& Connelly, 2006), we qualitatively explored the lived cultural, racial, and ethnic identities and self-images experienced by a Ghanaian-born female high school student, Akosua (pseudonym), as she navigated and resisted identities 
ascribed to her in the midwestern U.S. As noted by many scholars, narratives represent an ideal form for capturing such lived, experiential data (Clandinin \& Connelly, 1994; J. Kim, 2015). Using semistructured, open-ended interview as conversation (Kiramba \& Oloo, 2019) to collect and transcribe data, we then iteratively reconstructed that data within a (three-dimensional) narrative inquiry space of temporality, sociality, and place (Clandinin et al., 2012) using a NIDALS framework (Razfar \& Rumenapp, 2013) to read across Akosua's narrative for "resonant threads of patterns" (Clandinin et al., 2012, p. 10).

In analyzing participant narratives of lived experience, we aimed to construct and retell narrative accounts which reflected Akosua's experience relative to the two research questions that informed this study. We shared drafts of the narrative accounts with Akosua for her feedback. This led to revisions of the narrative accounts until the participant was satisfied that the accounts accurately represented who they were and were becoming (Clandinin et al., 2012). We identified the central meanings in the study participant's story as well as the common threads across her narrative accounts (James, 2018; Oloo \& Kiramba, 2019).

\section{Results}

\section{Narrative account of Akosua}

Originally from Ghana, Akosua currently lives with her parents and two brothers in a midwestern U.S. city and is in grade 11 (17 years old) at a large urban school. Akosua and her family immigrated to the Midwest in 2014. Both of her parents originate from the same ethnic group in Ghana and speak Ewe as their mother tongue. The family also speaks Nzema, a local language in Ghana used as an LOI in the lower primary school Akosua attended. Akosua and her brothers learned English-or as Akosua refers to it, "Ghanaian English"- in Ghana as English is the LOI from grade 4 onward.

At home, Akosua speaks Ewe, Nzema, and Kru English (also known as Ghanaian Pidgin). She speaks Kru English with friends and family from/in West Africa. At school, and with everyone else, she speaks what she calls "American English." Moreover, like many teens, Akosua 
uses social media often to communicate with friends. For connections in Africa, she mainly uses Kru English while using "proper English” to communicate with friends in the U.S. She is also considering taking French language lessons.

Across this mosaic of Akosua's multilingualism, she noted that her home languages are very valuable to her, both for the D-identity connections they afford back to people in Ghana (should she visit or return), but also because they are sometimes recognized by people in the U.S. as a mark of distinction. For example, "When my mom and I are speaking in our language, we have had people say, 'Wow, what language is that? I wish I could speak a different language other than English.' I think it's a very fun thing to have a different language from English."

Akosua emphasized the systemic support for multilingualism in her Ghanaian school setting in contrast to the specialized or more narrow support in the English language learner (ELL) level 2 class, to which she was assigned in the U.S. In Ghana, they used three main languages: "Majority of the students would speak Nzema, but we also used English and pidgin languages,” including Kru English. Importantly, Akosua noted that she had never seen any written Kru English (curricular) materials, adding that, "The Kru is not for any purpose. It's just for fun." When asked to elaborate on this point, Akosua stated that until grade 3, the LOI was Nzema, and that English could be used when referring to English books, with Kru English spoken mostly only to help students understand things, as an informal (but integral) scaffolding technique. From grade 4 onward, however, the LOI was English:

Sometimes, in the schools that I went to, if you could not speak English, you were allowed to use any other languageNzema and Kru were the most common. The [school] wanted students to speak English. [However,] the students were so used to speaking their [home] languages that they could ignore English. So, when it is time for many of the students to do something in class, it is hard for them to read or to communicate in English. While the teachers generally tried to make students speak in English, most teachers used a method that the students liked: English and native languages would 
have equal time in the classroom. There is time for English only, and then another time for native language. When it is time to speak the native language, you cannot speak English.

The ELL level 2 classroom setting in the U.S. afforded something like this multilingual (D-identity) support, albeit more narrowly. Akosua also reported a significantly different attitude toward nonstandard English in this space.

I felt welcomed there [at ELL classroom]. It was a place where I met so many children from Africa who I became friends with. Some of the children did not know how to speak English well, so we learned from each other. When I'm around there I'm so happy because if someone says something incorrectly, I can correct them because I also got corrections and encouragement from others. Usually, when someone gets feedback on what they have said, they feel happy. That's my fellow student; I am learning something from them. I feel happiest when I make them know that I'd like them to be successful. I am committed to my fellow students. I give them feedback, and they give me feedback too because that's the most important thing since we both learn in a fun environment. ... [Also] At ELL you could learn freely because the students there are not perfect and I'm not trying to be perfect in the presence of people that are perfect [such as in the general classroom where] because I will feel embarrassed when I say something grammatically incorrect. So being at ELL, we are all learning English and if you say something that is wrong they don't laugh at you. Well, I'm not saying that other people laugh but I'm just saying that if you're in the other classes and you speak something and other people don't understand what you are saying, sometimes you even feel like laughing at yourself. (italics added)

Initially startled and confused by the sometimes stark differences between her (D-identity) Ghanaian English and the "American English" she encountered after immigrating, Akosua also described her prior experiences with Kru English in Ghana as helping her to more 
easily acquire “American English.” Consequently, she expressed S-identity empathy with other ELL students who were having a harder time than she was learning English. When asked about the students who struggled with English and how they participated in the classroom during "English-only" time, Akosua noted:

Such students tended to be silent during English time, but very active when native languages were allowed. But for us, the place we were raised from, speaking English was not a problem for us. We could speak broken English before we started school. But that was not the case for other kids. Also, during English-only time in the classroom, we could make it straight [speak grammatically correct English] whenever the teacher was near. And when the teacher is gone, we could speak broken [English] or Pidgin.

Akosua's own experiences communicating with people when she first came to the U.S. were also marked with silence. She noted:

It was extremely hard. I couldn't even talk to people. I had to be quiet and the only time I could speak to someone was when I had to speak with teachers. Things got better with time as I became more eloquent and confident. But looking back, I never thought that I could be able to speak the way I am speaking right now [American English]. I thought I would be stuck with Ghanaian language. We have different accents than what they use here. So it gets weird because we are saying the same things, but it's weird...And I had to learn it in order to graduate. Like you need to know how to speak it right in order to get better and further in education and other stuff.

While Akosua reported cases of the typical biases and negative Lidentity perceptions often ascribed by teachers towards foreign-born learners in the U.S., two major elements helped to offset this educational obstacle: Akosua's own determination to succeed academically and acquire English, and support she received from a teacher, Miss Williams. Regarding her own (L-identity) determination, Akosua 
reframed her challenges as an opportunity but also acknowledged the "head start" she had:

My teachers knew that I spoke broken English. But that was an advantage for me because then I could improve on my English language skills, unlike my [ELL] classmates who had no knowledge of English. And that was the easiest way to continue for me to move further. Because, if it wasn't for Kru English, I think I would still be in ELL level 2 class. I know students that I started together with, but they are still finding it difficult, and they are still in level 2. And when they speak English, sometimes I don't understand them, and this makes me feel bad because they were here before me.

Akosua emphasized that not all of her teachers ascribed negative L-identities, noting that some provided encouragement: "[My teachers] knew I could say some stuff in English but just like I couldn't say the way they say it. They encouraged me to know how to say things and when to say them." One teacher in particular, Miss Williams, drew special emphasis from Akosua. Notably, Akosua asserted an A-identity link to her teacher (as part of her L-identity as a student), stating, "Miss Williams always inspires me. Her life and my life are almost the same, apart from the fact that she was brought up with correct English" (italics added). She added:

She also had to learn new stuff. She always encourages me and right now when I talk to her she is like "You have the opportunity, you need to be great. Just focus on what you're doing." That is what she tells me every time. That you can learn English as long as you put your heart into it. So, I was like, yeah, I can speak English. Every time I go to her office, I try so hard to speak English with her. I try so hard to make her understand what I'm saying. [Also] When I first came here, teachers would make me repeat several times what I had said. But when I spoke with Miss Williams, she immediately understood what I was talking about. Even when I was not clear, she would take her time and be patient with me because she knew that English was not my first language. Miss 
Williams knew that I had a native language that I spoke often and speaking English would take me some time to get used to. Other teachers did not understand that, so I had to repeat myself several times and yet it is all English. (italics added)

Akosua also highlighted the importance of the support she was getting at school and positive reinforcement on her writing. Not only would Miss Williams call to check on Akosua's progress:

One time she told me, "Why are you even in high school? You are so smart and should be in college or something right now." And I'm like, no, really? I still have some things to work on, but, like, I feel happy when she feels that way. It also makes my teacher feel proud not just of me, but of herself too.

This obviously affected a shift in Akosua's L-identity as a student, not suspecting previously that she was (already) college material.

While Akosua's teachers could sometimes acknowledge the importance of her languages for enhancing English proficiency, they neither encouraged her nor had the intellectual resources to speak to her in those languages. Only her family (or other Africans through social media) had that ability. As such, an I-identity "English-only" school setting outside of ELL class at best provided a neutral and unsupportive (when not hostile) identity ascription in contrast to her home-setting, which supported and honored those languages. As such, Akosua could report a stark exception to this rule from a time when she met a fellow African student at school:

She was three grades ahead of me. She was from Congo but the way she spoke English you would think that she was from here [the U.S.]. When we first met, she knew that I was an African because of my dress. She knew I was new, and she approached me saying, "Hi, where are you from?” And I was like, "I'm from Ghana." And instantly her accent changed. She started speaking Kru. I was happy someone could understand what I was saying without having to make things clear or say the same thing again for them to understand. So, I was very 
happy because she was able to communicate with me in $\mathrm{Kru}$ (italics added).

Much as Akosua made an A-identity link with Miss Williams to support her (L-identity) as a student, this older African peer may have similarly provided a role model for Akosua in a sense as well. To the extent that the older student approaches a new (younger) student and provides an A-identity and D-identity link in an otherwise apathetic or unfriendly language situation by immediately changing her accent and speaking in Kru, Akosua later positioned herself as well as someone who wanted to help others not suffer from the challenges she faced in school herself: "If somebody comes to my school from Africa I want to talk to them, and I want them to feel good, and help them so that they do not face the same challenges I faced."

Communication with other students was not always fun and exciting for Akosua and could have negative A-identity effects as well. Sometimes these arose from simple omission. For instance, because little to no time was devoted in Akosua's classrooms to any discussion of the students' cultures or heritage, she was astonished during one such rare discussion to learn how much her background resembled one of her peer's: "We had many things in common and I was like, 'How come I never knew this? Why?' Because we never got a chance to talk about it in class." In contrast to these missed classroom opportunities, negative A-identity effects could also arise through commission. When struggling to express herself in class and during group work, for instance, Akosua's peers often expected her to speak African American English:

Because they like see my skin color, so what they were expecting was for me to be like an African American, speaking the way African Americans speak. But when I spoke out, trying to give my opinion, they all looked at me and they were like, "What are you saying?" They did not say it out loud, but looking at their faces you could tell what they were thinking. The teacher too could not understand what I was saying.

Whether strictly understood as social constructs or cultural reifications, race, gender, sex, and ethnicity can provide fundamental 
self-identifications. For Akosua, like many from Africa, these N-identity factors constellate around the term "African" itself. Proud of her cultural identity, Akosua described herself as follows:

I am true born and raised African. Because I don't want to be around people that see you and judge you strictly by your skin color. Most people here when they look at me they know me as an African American. Just looking at me, the way I dress, because you have to dress like them, or else you will not fit in. But being like them doesn't mean to be exactly like them. You can dress and speak like them but still maintain your background. So, ... I still have my African spirit and culture in me. I'm happy right now I can speak Kru and English too. ... I am proud to know where I am from and to make people know that. It is the most important thing. Whenever I interact with other people, I don't want them to look at me and just decide who I am. If they want to know me, they should really ask rather than form an assumption about who I am. (italics added)

The specificity of her cultural heritage, her facility in multiple languages besides English, and her distinctness (both for peers and adults in the school system) from people with African American backgrounds all help to generate her "essential" (N-identity) sense of self. "If you know me, you understand I'm an African. I was born and raised in Africa. I have a culture that I have to go by. I have things that I had to do in order to like walk by my culture" (italics added). Nonetheless, this also comes with alienation, "feeling like you don't belong due to the background that you found here":

When I was still new at my school, there were so many students. Who are you going to talk to? Who are you going to share your story with? Who are you going to like sit down and be like, oh, I want to talk to you, I want to know about you, I want to like share my pain with you and I want you to share yours with me. And sometimes people don't even care.

Akosua expressly framed indifference towards knowing others as distinctly not African. So, while she expressed an appreciation for 
these opportunities to "sit" with others and learn about them, being incorrectly ascribed identities (by teachers or peers) provided a "a very bad experience" to have to go through. Immediately having said this, however, Akosua resiliently reflected, "But anyways, it's good. It's good because you've learned something. You've learned that not everyone understands you. And there are some people ... always ready to listen and always ready to know the kind of person you are, and some people just don't care."

Related to incorrectly ascribed identity, Akosua also noted peer pressure and expectations to act differently than her African culture. Akosua resists this: "So, maintain who you are and me maintaining mine, it's just perfect. If you're ready to go with me, I'm ready to go with you. Like, I don't have to be like you or do what you're doing in order to fit in" (italics added). This sometimes subtle, sometimes blunt, command to conform to non-African culture could surface in questions about why Akosua dressed and kept her hair the way she did. She resisted this in specifically essentialist (N-identity) terms, "I'm like, because I don't want it that way. And because this is my nature, like this is the way I was created. So, if you have a problem with it, then just go." It was precisely this kind of threatened erasure of her fundamental (N-identity) self that prompted Akosua to declare, "I think it's a very bad experience having to go through all this. But anyways, it's good. It's good because you've learned something. You've learned that not everyone understands you."

\section{Themes and discussion}

\section{Ascribed identities}

Who am I? Am I African? African American? American? Do I need to choose, or can I just be me?

As simple as these questions may be, they are complex for an immigrant youth who is struggling with defining her sense of self in an environment with less support than is optimal. In particular, language ideologies play a key role in how Akosua sees herself. After being assessed at her new school, Akosua was placed in an ELL level 2 class. Relative to her own facility, and what she noted in the shortfalls in 
other ELL classmates, the (I-identity) ELL level 2 setting applied an ascribed identity that affected and interacted with Akosua's shifting Lidentity as she moved from novice toward (still future) expert English speaker. Initially concerned that she might be "stuck with Ghanaian language" only, her D-identity gradually emerges (Gee, 2000-2001) as she becomes more eloquent, confident, and able to have more discourse with others at school.

This not only speaks to how identity is continuous across contexts but also intimately links to language and implications for pedagogy. The positive relationship between Akosua and her teacher, Miss Williams, exemplifies this. The teacher's encouragement not only supports and describes the L-identity it takes to be good in English but also reinforces the idea that Akosua's I-identity as an ELL student (with all of its potentially negative connotations that may come with being an English language learner) should not be taken as meaning Akosua is not smart. This involves not just her cognitive abilities (and not demeaning them), but her whole self. Meeting a fellow, older student, who spoke perfect English but immediately switched to Kru English when she recognized Akosua's African background allowed a powerful sense of belonging in a school setting where Akosua could easily feel that she did not belong. Similarly, despite language challenges (Didentity) in communicating with Miss Williams, Akosua explicitly described her teacher as being just like her "apart from the fact that she was brought up with correct English."

In a related way, Akosua also describes continually resisting ascribed identities by asserting her unique and African identity. In his seminal work on the education of minority students in U.S. classrooms, Ogbu (1978) wrote about the notion of African American children "acting and sounding White" (p. 49) at school. For young people, there sometimes is pressure to fit in or be seen to be cool. From Ogbu's analysis, this involves not just action, but also language and shifting identities. While Ogbu is not without his critics (see for example, Akom, 2008; Archer-Banks \& Behar-Horenstein, 2012; Foley, 2004; Matusov et al., 2010), his work is relevant to this study. Four decades after the publication of Ogbu's book, Akosua-an African immigrant high school student in the Midwest-can proudly insist:

I'm different. I'm from a different culture and I have different ways of dressing, just be cool with it, like be cool with 
it because I don't have to question what you do or like the kind of way you dress. Why? .... because this is my nature, like this is the way I was created. So, if you have a problem with it, then just go. If you are really interested in knowing, ask me in a nicer way.

\section{Invisible identities and in-betweenness}

Akosua identifies her culture and multilingual competencies as being central to who she is and is becoming. Her multilingual identity affords membership in different groups-with "American English" used for the classroom and U.S. friends, Kru English for family and African friends-and helps display Akosua's sense of uniqueness. Although a more accomplished (Ghanaian) English speaker in Ghana, in the U.S., little or no support for her languages meant she was always "quiet and only spoke when she had to" while struggling to master "their English."

Akosua problematizes assumptions and ascribed (institutional) identities about who she is. She notes how her peers and teachers ascribed her identity as African American, thereby erasing or not recognizing her "African" (multilingual, cultural, and background) identity, which she describes as "the most important thing." She notices (negative) D-identity and I-identity effects when she doesn't speak American or African American English. Out of this circumstance, she developed an in-between identity, where she was fine identifying as an African American on condition that people understood her cultural background; "If you know me, you understand I'm an African. I was born and raised in Africa. I have a culture that I have to go by. I have things that I had to do in order to like walk by my culture. If you understand that and you still call me an African American, I don't have a problem with it." Bhabha (1994) writes that there is a space "in-between the designations of identity" and points out that "this interstitial passage between fixed identifications opens up the possibility of a cultural hybridity that entertains difference without an assumed or imposed hierarchy" (p. 4).

Honoring her difference yet fitting in became a key challenge for Akosua's identity overall. Nonetheless, Watson and Knight-Manuel (2017) argue that Black identities often remain invisible. Related research documents problems of invisibility for African immigrant 
students specifically, including racialization, linguistic and accent differences, and stereotyping (Allen et al., 2012; Kumi-Yeboah \& Smith, 2017). We would add that the institutional (I-identity) factor that conflates African American and African students (never mind the immense variation of ethnic cultures among immigrants from Africa) reproduces at a systemic level the key challenge Akosua faced at the personal level.

Of course, this focus on identity at school too narrowly conceives it. In her home life, Akosua does not face the (negative) ascribed identities associated with her (D-identity) languages. In her social media interactions with friends in Africa as well, Akosua's multilingual (Didentity), African (N-identity) self is not hemmed in or constrained by the kind of ascribed identities experienced in the school setting. This reflects, as Hall (2004) paraphrases it, Hegel's recognition that "an individual's self-consciousness never exists in isolation, that it exists in relation to an 'other' or 'others' who validate its existence" but casts doubt on the insistence that "this relationship is not one of inherent equality or mutual interpersonal validation; for Hegel, it always results in a struggle for domination" (p. 51). Instead, this identity validation can at times come from others through nondominating face-to-face interaction, discursive identity, and shared experiencesin brief, from an A-identity affinity. Certainly, the ubiquitous African humanistic notion of Ubuntu, "I am, because others are," does not require or imply an implicit struggle for domination in identity itself. Neither do Akosua's experiences in her home life, in social media interactions with friends in Africa, the support she received from Miss Williams, the greater sense of welcome in ELL level 2, or the unexpected pleasure of an older peer addressing her in Kru English, otherwise largely absent in her school setting.

\section{Language hierarchies}

In highlighting the connection between language and identity, Razfar (2012) asks the seemingly simple and commonsensical questions: "What language should be learned?" and "What language is most worthwhile?” (p. 128). In any given setting, the answer(s) to such questions will implicate a more or less articulated, hierarchical valuation of languages. For Akosua in her school setting, the hierarchy was 
English first, with all other languages as second or not acknowledged. She reported that sometimes when people would hear her speaking non-English, they might ask if it were Spanish, French, or even Korean-an "African" language crossed no one's mind. Acknowledging her multilingual assets, Akosua noted:

It makes me feel good. Saying something that another person doesn't speak and understand is always cool. They be like wow! Is that a language too? I'm like, yes, because you heard it. Most kids who grew up with English only think it is weird to speak several languages. The only languages they know are Spanish, Korean, and French. Sometimes when you speak, they will ask, "What are you speaking? Is it French?" "No, it is not." "Is it Spanish?" "No, it is not." And when you finally tell them, they be like, is that even a language? I'm like, yes, it is. (italics added)

At home, in contrast, Nzema, Ewe, Kru, and both Ghanaian and American English could occur as various situations called for them, in a less explicitly hierarchical arrangement.

Differential legitimacy accorded to different languages not only obscures the linguistic identity of African immigrants but also creates needless obstacles to school success overall when delegitimized languages are treated as problems (that the immigrant must overcome) rather than utilized as a resource (by people in the contexts wherein they occur) (Kiramba, 2018). Thus, despite her greater facility in Ghanaian English compared to her peers in Ghana, her "broken English" (as she now calls it) prompted an ascribed (I-identity) designation as an ELL level 2 student and was generally not met with support or a sufficient effort or will (from most teachers and peers) to understand her in the school setting as she struggled to communicate (D-identity). While we can acknowledge that it may be difficult to afford teacher (and peer) resources able to leverage, rather than marginalize or ignore, immigrant student funds of knowledge (L-identity), we should neither pretend that it can only be the responsibility of a young person to provide an adequate education for themselves in school nor believe that we benefit nationally and culturally from failing such students in school. 
Given that even very young children can grasp hierarchical patterns of inclusion or exclusion, language hierarchies in high school will have an obvious, and likely chilling, effect on student L-identity and academic performance. While the ferocity of Akosua's ( $\mathrm{N}$-identity) will to succeed academically at English acquisition and school generally is self-evident and admirable, we should neither believe (nor require) that every immigrant student have the resources needed for such resilience. While Akosua had the resources and support to reflect, "I think it's a very bad experience having to go through all this. But anyways, it's good. It's good because you've learned something," for students without that support or resources required to make such a resilient turn, only the very bad experience remains for them, with all of its personal (psychological) and sociological (national) consequences educationally.

\section{Conclusion and implications}

While the NIDALS model of situated and discursive identity highlights multiple layers of factors that constellate into a sense of identity overall, as an analytic lens, it especially affords taking "cross-sections" of situational behavior in order to understand how someone linguistically frames or describes various decisions, choices, and interactions in those situations (Razfar \& Rumenapp, 2013). For Akosua, confronted by an educational setting where the prevailing language hierarchies did not support her multilingual D-identity, she particularly navigated various ascribed identities at school-especially an implication of developing English proficiency as an (I-identity) ELL level 2 student, her ascribed (N-identity) African American-through a combination of (1) supportive (A-identity) affinities with fellow ELL students, a supportive teacher, and an older peer who addressed her (at school) in one of her home languages; and (2) her strong ( $\mathrm{N}$-identity) assertion of herself as an African. As a "very bad experience" that she nevertheless had resources for and found a way to turn around, this also became a part of her (S-identity) with others who might be suffering in the same way; she actively took on a sense of identity to see that others would not have to go through what she did.

To achieve the national goals of education and its consequent benefits to the country and economy overall, meeting the psychological 
requirements of all students is prerequisite. Razfar and Rumenapp (2013) emphasize this when they write, "When we see our whole SELF in the OTHER then we are ready to teach and embark on a collective journey of mind, body, and heart" (p. 22). If this seems to suggest that teachers should purposefully and consciously embark on a journey of learning about the students in their classrooms, then recognizing that the students themselves are the already present experts in the room on that matter reveals where school administrators and teachers can find the needed curricular materials for this proposal.

In other words, once we are thinking of our students through a NIDALS identity approach, then this immediately opens up a fuller context for our students' (S-identity) development. We suggest not that students should set the curricular content of any course but that how educators deliver that content can (and should) be guided by the already present funds of knowledge and competencies (L-identities) of students. In practice, this particularly means avoiding not only any implications of (I-identity) in students, regardless of past educational achievement or failure, but also any implications of (D-identity) "feelings of inferiority" or "erasure" due to language hierarchies, which students can readily perceive.

To frame this in a way that sounds more familiar, we must especially challenge any reproduction of linguistic and racial inequality in schools and society. As Wolfenstein (1993) demonstrates, language represents a key site in this effort, because language use can abet these inequalities even when users of that language oppose it. As such, while this explicitly requires challenges to existing linguistic hegemony, the task involves nothing more difficult than acknowledging all languages (not just majority dialects or LOI) as valuable and useful resources. Here again, the point is not that we must accept the content of any student language use as unassailable and correct but that such usage not only indicates how the student expresses (D-identity) themselves but also the communicative route (as the only communicative route available at that moment) that an educator must take to be heard by the student. If Wolfenstein (1993) correctly notes that (for students in U.S. educational contexts) "If you don't speak white you will not be heard" (p. 331), the corollary for educators is that "If you don't speak 'student' you will not be heard" as well. While the blunt truth of this may be easy to miss in various LOI policy recommendations, the experience of a nonexpert immigrant language speaker (and student) 
throws this truth into unmistakable relief; as Akosua reported, "Like, when I first came [to the school] and we went to the ELL education office. So this lady was talking and I was like, 'What is she even saying?" Recognizing the woman's speaking as English, it was nonetheless no English Akosua yet knew. Self-evidently, if the goal of an educational system (both pedagogically and administratively) is to deliver content to students, then to require those students (as message recipients) to somehow be responsible for how those messages are generated is not only bizarre but also a shirking of responsibility.

Here again the seeming difficulty of speaking "student" to all students remains only when student funds of knowledge and competencies (L-identity) go unrecognized or denigrated. As a matter of desperate convenience or shortages of resources, school systems may perpetuate state-sponsored linguistic norms, ideologies, and identities in an attempt simply to get the job done. But when educators instead draw on students as resources already in the room in order to find ways of negotiating and undermining language hierarchies and the ascribed identities they support, this allows all students, including multilinguals, to have their identity affirmed, even in school systems that have historically marginalized them. This, in turn, supports educational achievement, broadly realized, not only psychologically for all students but also economically and nationally for the country-a critical accomplishment in an era when educational quality in the U.S. is losing ground to foreign achievements.

\section{References}

Agyepong, M. (2013). Seeking to be heard: An African-born, American-raised child's tale of struggle, invisibility, and invincibility. In I. Harushimana, C. Ikpeze, \& S. Mthethwa-Sommers (Eds.), Reprocessing race, language and ability: African-born educators and students in transnational America (pp. 155168). Peter Lang.

Akom, A. A. (2008). Black metropolis and mental life: Beyond the "burden of 'acting white"” toward a third wave of critical racial studies. Anthropology \& Education Quarterly, 39(3), 247-265. https://doi. org/10.1111/j.1548-1492.2008.00020.X

Allen, K. M., Jackson, I., \& Knight, M. G. (2012). Complicating culturally relevant pedagogy: Unpacking African immigrants' cultural identities. International Journal of Multicultural Education, 14(2). http://dx.doi.org/10.18251/ijme. $\underline{\mathrm{v} 14 \mathrm{i} 2.506}$ 
Archer-Banks, D. A., \& Behar-Horenstein, L. S. (2012). Ogbu revisited: Unpacking high-achieving African American girls' high school experiences. Urban Education, 47(1), 198-223. https://doi.org/10.1177/0042085911427739

Awokoya, J. T. (2013). “They can't teach what they don't know”: Insights from teacher professional development workshops on Africa. In I. Harushimana, C. Ikpeze, \& S. Mthethwa-Sommers (Eds.), Reprocessing race, language and ability: African-born educators and students in transnational America (pp. 89105). Peter Lang.

Bhabha, H. (1994). Location of cultures. Routledge.

Brady, J. (2015). Dialect, power and politics: Standard English and adolescent identities. Literacy, 49(3), 149-157. https://doi.org/10.1111/lit.12058

Brown, B. A. (2015). Discursive identity and conceptual continuity: Using informal science literacy to promote students science learning. Stanford University, Environmental Molecular Science Institute Teacher Workshop. https://emsiteacherworkshop.stanford.edu/pages/workshopresources/ DiscursiveIdentityConceptualContinuity.pdf

Butler, I., \& Kois, D. (2018). The world only spins forward: The ascent of "Angels in America.” Bloomsbury.

Clandinin, D. J., \& Connelly, F. M. (1994). Personal experience methods. In N. Denzin \& Y. Lincoln (Eds.), Handbook of qualitative research (pp. 413-427). Sage.

Clandinin, D. J., \& Connelly, F. M. (2006). Narrative inquiry: Experience and story in qualitative research. Jossey-Bass.

Clandinin, D. J., Lessard, S., \& Caine, V. (2012). Reverberations of narrative inquiry: How resonant echoes of an inquiry with early school leavers shaped further inquiries. Educação, Sociedade \& Culturas, 36, 7-24.

Covington-Ward, Y. (2017). "Back home, people say America is Heaven”: Premigration expectations and post-migration adjustment for Liberians in Pittsburgh. Journal of International Migration and Integration, 18(4), 10131032. https://doi.org/10.1007/s12134-017-0511-7

Creese, G. (2010). Erasing English language competency: African migrants in Vancouver, Canada. Journal of International Migration and Integration/Revue de l'integration et de la migration internationale, 11(3), 295-313. https://doi. org/10.1007/s12134-010-0139-3

Darling-Hammond, L. (2010). The flat world and education: How America's commitment to equity will determine our future. Teachers College Press.

Dávila, L. T. (2019). Multilingualism and identity: Articulating "African-ness" in an American high school. Race Ethnicity and Education, 22(5), 634-646. https://doi.org/10.1080/13613324.2018.1424709

Foley, D. (2004). Ogbu's theory of academic disengagement: Its evolution and its critics. Intercultural Education, 15(4), 385-397. https://doi.org/10.1080/14675 98042000313412

Gee, J. P. (2000-2001). Identity as an analytic lens for research in education. Review of Research in Education, 25, 99-125. https://doi.org/10.2307/1167322 
Ghong, M., Saah, L., Larke, P. J., \& Webb-Johnson, G. (2007). Teach my child, too: African immigrant parents and multicultural educators sharing culturally responsive teaching tips. Journal of Praxis in Multicultural Education, 2(1), 6169. https://doi.org/10.9741/2161-2978.1023

Gluszek, A., \& Dovidio, J. F. (2010). Speaking with a nonnative accent: Perceptions of bias, communication difficulties, and belonging in the United States. Journal of Language and Social Psychology, 29(2), 224-234. https://doi. org/10.1177/0261927X09359590

Hall, D. E. (2004). Subjectivity. Routledge. https://doi. org/10.4324/9780203644072

Hersi, A. A. (2011). Immigration and resiliency: Unpacking the experiences of high school students from Cape Verde and Ethiopia. Intercultural Education, 22(3), 189-202. https://doi.org/10.1080/14675986.2011.592033

James, N. (2018). Using narrative inquiry to explore the experience of one ethnically diverse ESL nursing student. Teaching and Learning in Nursing, 13(1), 35-40. https://doi.org/10.1016/j.teln.2017.08.002

Kim, J. (2015). Understanding narrative inquiry: The crafting and analysis of stories as research. Sage.

Kim, S. (2018). "It was kind of a given that we were all multilingual": Transnational youth identity work in digital translanguaging. Linguistics and Education, 43, 39-52. https://doi.org/10.1016/j.linged.2017.10.008

Kiramba, L. K. (2017). Multilingual literacies: Invisible representation of literacy in a rural classroom. Journal of Adolescent \& Adult Literacy, 61(3), 267-277. https://doi.org/10.1002/jaal.69o

Kiramba, L. K. (2018). Language ideologies and epistemic exclusion. Language and Education, 32(4), 291-312. https://doi.org/10.1080/09500782.2018.14384 $\underline{69}$

Kiramba, L. K. (2019). Heteroglossic practices in a multilingual science classroom. International Journal of Bilingual Education and Bilingualism, 22(4), 445-458. https://doi.org/10.1080/13670050.2016.1267695

Kiramba, L. K., \& Harris, V. J. (2019). Navigating authoritative discourses in a multilingual classroom: Conversations with policy and practice. TESOL Quarterly, 53(2), 456-481. https://doi.org/10.1002/tesq.493

Kiramba, L. K., \& Oloo, J. A. (2019). "It's OK. She doesn't even speak English”: Narratives of language, culture, and identity negotiation by immigrant high school students. Urban Education. https://doi.org/10.1177/0042085919873696

Kumi-Yeboah, A. (2016). Educational resilience and academic achievement of immigrant students from Ghana in an urban school environment. Urban Education. https://doi.org/10.1177/0042085916660347

Kumi-Yeboah, A., \& Smith, P. (2017). Cross-cultural educational experiences and academic achievement of Ghanaian immigrant youth in urban public schools. Education and Urban Society, 49(4), 434-455. https://doi. org/10.1177/0013124516643764 
Malsbary, C. B. (2014). "It's not just learning English, it's learning other cultures": Belonging, power, and possibility in an immigrant contact zone. International Journal of Qualitative Studies in Education, 27(10), 1312-1336. https://doi.org/1 0.1080/09518398.2013.837210

Matusov, E., DePalma, R., \& Smith, M. P. (2010). The creation and maintenance of a "learning-loving minority" in conventional high schools: A research-based response to John Ogbu. Oxford Review of Education, 36(4), 463-480. https:// doi.org/10.1080/03054985.2010.491186

Medvedeva, M. (2010). Perceived discrimination and linguistic adaptation of adolescent children of immigrants. Journal of Youth and Adolescence, 39(8), 940-952. https://doi.org/10.1007/s10964-009-9434-8

Miller, J. P. (2010). Whole child education. University of Toronto Press.

Mwangi, C. A. G., \& English, S. (2017). Being Black (and) immigrant students: When race, ethnicity, and nativity collide. International Journal of Multicultural Education, 19(2), 100-130. https://doi.org/10.18251/ijme.v19i2.1317

Nava, R. G. (2001). Holistic education: Pedagogy of universal love (M. N. Rios \& G. S. Miller, Trans.). Holistic Education Press.

Obsiye, M., \& Cook, R. (2016). Forum: Cultural identity and (dis)continuities of children of immigrant communities. Cultural Studies of Science Education, 11(4), 1061-1070. https://doi.org/10.1007/s11422-015-9706-4

Ogbu, J. (1978). Minority education and caste: The American system in crosscultural perspective. Academic Press.

Okonofua, B. A. (2013). "I am Blacker than you": Theorizing conflict between African immigrants and African Americans in the United States. SAGE Open, 3(3), 1-14. https://doi.org/10.1177/2158244013499162

Oloo, J. A. (2016). A narrative and post-/anti-colonial approach to understanding the experiences of foreign certified teachers in rural Saskatchewan schools. PhD thesis, Faculty of Graduate Studies and Research, University of Regina, Canada.

Oloo, J. A., \& Kiramba, L. K. (2019). A narrative inquiry into experiences of Indigenous teachers during and after teacher preparation. Race Ethnicity and Education. https://doi.org/10.1080/13613324.2019.1604507

Razfar, A. (2012). Language ideologies and curriculum studies: An empirical approach to "worthwhile" questions. Journal of Curriculum Theorizing, 28(1), 127-140. https://journal.jctonline.org/index.php/jct/article/view/248

Razfar, A., \& Rumenapp, J. C. (2013). Applying linguistics in the classroom: A sociocultural approach. Routledge. https://doi.org/10.4324/9780203095195

Schroeter, S., \& James, C. E (2015). "We're here because we're Black": The schooling experiences of French-speaking African- Canadian students with refugee backgrounds. Race Ethnicity and Education, 18(1), 20-39. https://doi. org/10.1080/13613324.2014.885419

Stake, R. E. (1995). The art of case study research. Sage.

Schwartz, S. J., Cano, M. A, \& Zamboanga, B. L. (2015). Identity development. In C. Suárez-Orozco, M. M. Abo-Zena, \& A. K. Marks (Eds.), Transitions: The development of children of immigrants (pp. 1-27). New York University Press. 
Ukpodoku, O. N. (2016). Perspectives of African immigrant parents on U.S. PK-12 school system. In O. N. Ukpodoku \& P. O. Ojiambo (Eds.), Erasing invisibility, inequity and social injustice of Africans in the diaspora and the continent (pp. 1-29). Cambridge Scholars Publishing.

Watson, V. W., \& Knight-Manuel, M. G. (2017). Challenging popularized narratives of immigrant youth from West Africa: Examining social processes of navigating identities and engaging civically. Review of Research in Education, 41(1), 279310. https://doi.org/10.3102/0091732X16689047

Watt, P. (2006). An intercultural approach to "integration." Translocations: The Irish Migration, Race and Social Transformation Review, 1(1), 154-163.

Wells, A. S., Fox, L., \& Cordova-Cobo, D. (2016). How racially diverse schools and classrooms can benefit all students. The Education Digest, 82(1), 17-24.

Wolfenstein, E. V. (1993). Psychoanalytic-Marxism: Groundwork. Guilford Press.

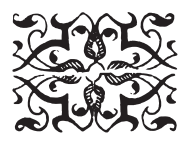

Lydiah Kiramba, Ph.D., < lkiramba2@unl.edu > is an assistant professor of educational linguistics at the University of Nebraska-Lincoln. Dr. Kiramba's research examines communicative practices of multilingual students in superdiverse classrooms, and literacies of migrants, immigrants and multilingual populations in K-12 classrooms.

James Oloo, Ph.D., < James.Oloo@uwindsor.ca > is an assistant professor of education at the University of Windsor, Ontario. Dr. Oloo's research interests include narrative inquiry, teacher narratives, urban education, and the education of immigrant and refugee students. 